\title{
Social Interaction and Cocaine Conditioning in Mice Increase Spontaneous Spike Frequency in the Nucleus Accumbens or Septal Nuclei as Revealed by Multielectrode Array Recordings
}

\author{
Kai K. Kummer ${ }^{a}$ Rana El Rawas ${ }^{a}$ Michaela Kress $^{b} \quad$ Alois Saria $^{a}$ \\ Gerald Zernig ${ }^{a, c}$ \\ ${ }^{a}$ Experimental Psychiatry Unit, and ${ }^{b}$ Division of Physiology, Medical University of Innsbruck, and ${ }^{\mathrm{c}}$ Department of \\ Psychology, University of Innsbruck, Innsbruck, Austria
}

\section{Key Words}

Multielectrode array - Cocaine-conditioned place preference $\cdot$ Social interaction-conditioned place preference $\cdot$ Spontaneous activity - Spike frequency . Nucleus accumbens · Septum

\begin{abstract}
Both cocaine and social interaction place preference conditioning lead to increased neuronal expression of the immediate early gene EGR1 in the nucleus accumbens, a central region of the reward pathway, suggesting that both drug and natural rewards may be processed in similar brain regions. In order to gain novel insights into the intrinsic in vitro electrical activity of the nucleus accumbens and adjacent brain regions and to explore the effects of reward conditioning on network activity, we performed multielectrode array recordings of spontaneous firing in acute brain slices of mice conditioned to either cocaine or social interaction place preference. Cocaine conditioning increased the spike frequency of neurons in the septal nuclei, whereas social interaction conditioning increased the spike frequency in the nucleus accumbens compared to saline control animals. In addition, social interaction conditioning decreased the amount of active neuron clusters in the nucleus accumbens. Our
\end{abstract}

findings suggest that place preference conditioning for both drug and natural rewards may induce persistent changes in neuronal network activity in the nucleus accumbens and the septum that are still preserved in acute slice preparations.

(c) 2015 S. Karger AG, Basel

\section{Introduction}

Dyadic social interaction constitutes the basis of psychotherapeutic interventions for addiction and other psychiatric disorders in humans [1-3]. In rats, only 4 episodes of social interaction are sufficient to not only reverse place preference from cocaine to social interaction, but also to inhibit the cocaine-induced reexpression of cocaine-conditioned place preference (CPP) $[4,5]$. Furthermore, in a concurrent CPP paradigm, intraperitoneal injections of $15 \mathrm{mg} / \mathrm{kg}$ cocaine and social interaction compete as rewards of the same reward strength $[4,6]$. Mice exhibit similar behavioral effects but with a higher sensitivity to cocaine [7]. When comparing the expression profiles of the immediate early gene (IEG) early

\section{A.S. and G.Z. contributed equally to the work.}

\section{Kai K. Kummer}

Experimental Psychiatry Unit

Medical University of Innsbruck

Innrain 66a, AT-6020 Innsbruck (Austria)

E-Mail kai.kummer@i-med.ac.at 
Table 1. Schedule of behavioral experiments

\begin{tabular}{|c|c|c|c|c|c|c|c|c|c|c|}
\hline & Day 1 & Day 2 & Day 3 & Day 4 & Day 5 & Day 6 & Day 7 & Day 8 & Day 9 & Day 10 \\
\hline $\begin{array}{l}\text { sal } \\
\text { coc CPP } \\
\text { int CPP }\end{array}$ & Pretest & $\begin{array}{l}\text { sal } \\
\text { coc } 1 \\
\text { int } 1\end{array}$ & sal & $\begin{array}{l}\text { sal } \\
\operatorname{coc} 2 \\
\text { int } 2\end{array}$ & sal & $\begin{array}{l}\text { sal } \\
\text { coc } 3 \\
\text { int } 3\end{array}$ & sal & $\begin{array}{l}\text { sal } \\
\text { coc } 4 \\
\text { int } 4\end{array}$ & sal & CPP test \\
\hline
\end{tabular}

The schedules for sal, coc and int CPP are shown.

growth response protein 1 (EGR1) - alias Zif268, KROX24, NGFI-A - after the acquisition and expression of CPP for either cocaine or social interaction, both conditioning stimuli lead to increased expression of EGR1 in the nucleus accumbens core and shell, which are central regions of the reward pathway as well as in other associated brain regions [8]. These results strongly support the idea that both natural and drug rewards are processed in similar brain regions [9-13].

The use of IEGs (e.g. EGR1 or cFos) as indicators of neuronal activation has the drawbacks of cell type expression specificity, since not all neurons in the central nervous system express all types of IEGs, as well as stimuluscoupling uncertainty [14]. Furthermore, IEG upregulation is slow as compared to electrical network activity upon immediate synaptic transmission [15].

In order to gain novel insights into the intrinsic in vitro electrical activity of the nucleus accumbens and adjacent brain regions and to explore the effects of reward conditioning on network activity, we performed in vitro multielectrode array (MEA) recordings of mice conditioned to either cocaine (as a prototypic drug reward) or social interaction (as a natural reward) as compared to nonconditioned controls.

In this study, we demonstrate for the first time that cocaine conditioning increased the spike firing frequency in the lateral/medial septal nuclei and social interaction conditioning increased spike firing in the nucleus accumbens. This suggests that reward conditioning by both drug and natural rewards may induce long-lasting changes in neuronal plasticity that are preserved in acute slice preparations of the above-mentioned brain regions.

\section{Materials and Methods}

Animals

Male C57BL/6N mice aged 8 weeks were obtained from Charles River Laboratories (Sulzfeld, Germany). The animals were housed at a constant room temperature of $24^{\circ} \mathrm{C}$ and had ad libitum access to tap water and pelleted chow (Tagger, Austria). The experiments were performed during the light phase of a continuous 12-hour light/dark cycle. The animals were individually housed for 7 days before the start of the behavioral experiments. All experiments were approved by the Austrian National Animal Experiment Ethics Committee.

\section{CPP Apparatus}

Conditioning of C57BL/6N mice was conducted in a custommade 3 -chamber CPP apparatus $(64 \mathrm{~cm}$ wide $\times 32 \mathrm{~cm}$ deep $\times 31$ $\mathrm{cm}$ high) made of unplasticized polyvinyl chloride. The middle (neutral) compartment $(10 \times 30 \times 30 \mathrm{~cm})$ had white walls and a white floor. Two doorways led to the 2 conditioning compartments $(25 \times 30 \times 30 \mathrm{~cm}$ each $)$ with walls showing either vertical or horizontal black-and-white stripes of the same overall brightness and with stainless steel floors containing either 168 holes (diameter $0.5 \mathrm{~cm})$ or 56 slits $(4.2 \times 0.2 \mathrm{~cm}$ each). The time spent in each compartment was video recorded and analyzed offline with manual timers. The CPP apparatus was cleaned with a $70 \%$ camphorated ethanol solution after each session. All experiments were performed under fluorescent ceiling light (58 W, $1 \mathrm{~m}$ distance) and device-generated white noise.

\section{Acquisition of Cocaine CPP}

For the acquisition of cocaine $\mathrm{CPP}$, the conditioning procedure consisted of a pretest session on day 1, 8 consecutive training days in an alternate day design ( 1 training session per day, a total of 4 training sessions each) and a CPP test on day 10 (table 1). The stimuli were either an intraperitoneal injection of $15 \mathrm{mg} / \mathrm{kg} \mathrm{co}-$ caine (weight given for the pure base, $\mathrm{HCl}$ salt dissolved in saline and injected at a volume of $10 \mathrm{ml} / \mathrm{kg}$ ) or only a saline injection. Pretest, training and CPP test sessions were of equal duration (15 min each). Pretest bias for any of the 2 conditioning chambers was declared if the animal spent more time in one of the conditioning chambers during the pretest session, and the initially nonpreferred chamber was subsequently paired with cocaine.

\section{Acquisition of Social Interaction CPP}

For the acquisition of social interaction CPP, the conditioning procedure consisted of a pretest session on day 1, 8 consecutive training days in an alternate day design ( 1 training session per day, a total of 4 training sessions each) and a CPP test on day 10 . The stimuli were either a 15-min dyadic social interaction session with a sex- and weight-matched male conspecific preceded by an intraperitoneal injection of $10 \mathrm{ml} / \mathrm{kg}$ saline or only a saline injection. Pretest, training and CPP test sessions were of equal duration (15 min each). Pretest bias for any of the 2 conditioning chambers was 
declared if the animal spent more time in one of the conditioning chambers during the pretest session, and the initially nonpreferred chamber was subsequently paired with social interaction.

\section{Saline Control Experiments}

For the saline control experiments, the procedure consisted of a pretest session on day 1, 8 consecutive training days (1 training session per day) and a CPP test on day 10 . The stimulus was an intraperitoneal injection of $10 \mathrm{ml} / \mathrm{kg}$ saline, followed by $15 \mathrm{~min}$ in the conditioning compartments for all training sessions.

\section{Slice Preparation}

Coronal slices were prepared from C57BL/6N mice. The animals were anesthetized 30-45 min after the start of the CPP test session with isoflurane (Forane ${ }^{\circledR}$, Abbott Laboratories) and decapitated. The brains were rapidly removed and immersed in icecold oxygenated $\left(95 \% \mathrm{O}_{2}, 5 \% \mathrm{CO}_{2}\right)$ artificial cerebrospinal fluid (aCSF) containing (in mmol/l): $\mathrm{NaCl} 125, \mathrm{NaHCO}_{3} 25$, D-glucose 25, $\mathrm{KCl} 2.5, \mathrm{NaH}_{2} \mathrm{PO}_{4} 1.25, \mathrm{CaCl}_{2} 2$ and $\mathrm{MgCl}_{2} 1$ [16]. The brains were trimmed with a scalpel blade and the remaining parts were glued onto the stage of a vibrating microtome (VT1200S, Leica Microsystems, Germany) to cut three $400-\mu \mathrm{m}$-thick coronal slices. The slices were incubated for $10-15 \mathrm{~min}$ in $32-34^{\circ} \mathrm{C}$ warm oxygenated protective aCSF [17] containing (in $\mathrm{mmol} / \mathrm{l}$ ): $\mathrm{N}$-methyl-D-glucamine 110, $\mathrm{HCl} 110, \mathrm{KCl} 2.5, \mathrm{NaH}_{2} \mathrm{PO}_{4} 1.2, \mathrm{NaHCO}_{3} 25$, D-glucose 25, $\mathrm{MgSO}_{4} 10$ and $\mathrm{CaCl}_{2}$ 0.5. After protective recovery, the slices were transferred to normal aCSF at room temperature and were allowed to recover for at least $1 \mathrm{~h}$ before they were used for electrophysiological recordings.

\section{MEA Recordings}

The slices were transferred to the 3D MEA (MEA60-200-3DGND, Quane Biosciences, Lausanne, Switzerland) chamber and fixed with a platinum-framed grid with nylon fibers (weight $\sim 0.3 \mathrm{~g}$ ). The MEA was then inserted into the recording apparatus (MEA2100-System, Multi Channel Systems, Reutlingen, Germany) and superfused with oxygenated aCSF at $32-34^{\circ} \mathrm{C}$ for at least $5 \mathrm{~min}$. Spontaneous action potential discharge activity was recorded with a sampling rate of $25 \mathrm{kHz}$, and the position of the brain slices on the electrode field was photographed on an inverted microscope (Carl Zeiss Microscopy GmbH, Jena, Germany) using a digital camera after recording.

\section{Data Analysis}

The recorded traces were analyzed using MC_Rack software (Multi Channel Systems). All data streams were $50 \mathrm{~Hz}$ high-passfiltered, and spike detection was performed with a threshold of 5 SD from noise. Electrodes were assigned to the respective brain region (nucleus accumbens, dorsal striatum or septal nuclei) according to the position of the electrodes on the photographs (fig. 1). As a small number of spikes was also recorded on reference electrodes, recording electrodes were classified as active if the spiking frequency exceeded $0.0333 \mathrm{~Hz}$. Mean frequencies per animal were calculated for the respective brain regions and used for correlation of spike frequencies versus time spent in the stimulus-associated compartments.

For statistical analysis, GraphPad Prism (Kruskal-Wallis H test followed by Dunn's multiple comparisons test and Mann-Whitney U test), IBM SPSS Statistics (Spearman correlation), GraphPad QuickCalcs ( $\chi^{2}$ for $2 \times 2$ contingency tables; http://graphpad.com/ quickcalcs/) or VassarStats ( $\chi^{2}$ for $4 \times 2$ or $3 \times 2$ contingency tables and Cohen's D; http://vassarstats.net/) were used as appropriate. The level of statistical significance was predefined at $\mathrm{p}<0.05$, and testing was always 2 -sided.

\section{Results}

\section{CPP for Cocaine and Social Interaction}

Mice conditioned to cocaine CPP developed a strong place preference for the cocaine-paired compartment (coc) compared to the saline-paired compartment (sal; fig. $2 \mathrm{a} ; \mathrm{n}=6$; Kruskal-Wallis $\mathrm{H}$ test, $\mathrm{p}=0.0055, \mathrm{H}=8.99$; Dunn's multiple comparisons test, coc vs. sal, $\mathrm{p}=0.016$ ), with 1 of 6 mice producing place aversion.

In 7 of 12 mice, social interaction conditioning also induced CPP, as characterized by significantly more time spent in the social interaction-paired compartment (int; fig. $2 c ; n=7$; Kruskal-Wallis $\mathrm{H}$ test, $\mathrm{p}=0.0016, \mathrm{H}=10.78$; Dunn's multiple comparisons test, int vs. sal, $\mathrm{p}=0.0089$ ). In contrast, 5 of 12 social interaction-conditioned mice developed conditioned place aversion (CPA), shown as significantly less time spent in the social interactionpaired compartment (fig. $2 \mathrm{~d} ; \mathrm{n}=5$; Kruskal-Wallis $\mathrm{H}$ test, $\mathrm{p}=0.038, \mathrm{H}=6.14$; Dunn's multiple comparisons test, int vs. sal, $\mathrm{p}=0.027$ ).

Control animals did not show any obvious preference (fig. $2 \mathrm{~b} ; \mathrm{n}=6$; Kruskal-Wallis $\mathrm{H}$ test, $\mathrm{p}=0.58, \mathrm{H}=1.22$ ).

\section{Electrical Activity in Different Brain Regions of}

Cocaine- and Social Interaction-Conditioned Mice

In order to explore the effects of conditioning on the network activity in the nucleus accumbens, we first assessed the proportion of electrically active neurons with spike frequencies $>0.0333 \mathrm{~Hz}$ in saline-treated, cocaineand social interaction-conditioned mice (fig. 3). In saline controls, the median action potential firing frequency was higher in the septal nuclei than in the nucleus accumbens and dorsal striatum (table 2; nucleus accumbens $0.07 \mathrm{~Hz}$, dorsal striatum $0.11 \mathrm{~Hz}$ and septal nuclei $0.28 \mathrm{~Hz}$ ). Also, the prevalence of electrically active sites was higher in the septal nuclei compared to the nucleus accumbens and dorsal striatum (table 3; nucleus accumbens $9.9 \%$, dorsal striatum $12.4 \%$ and septal nuclei $37.4 \%)$.

In the nucleus accumbens, the median spike frequencies of social interaction-conditioned mice were significantly higher than in saline control mice (table 2 ; sal 0.070 $\mathrm{Hz}, \operatorname{coc} 0.093 \mathrm{~Hz}$, int $0.12 \mathrm{~Hz}$; Kruskal-Wallis $\mathrm{H}$ test, $\mathrm{p}=$ $0.019, \mathrm{H}=7.94$; post hoc Dunn's multiple comparisons 


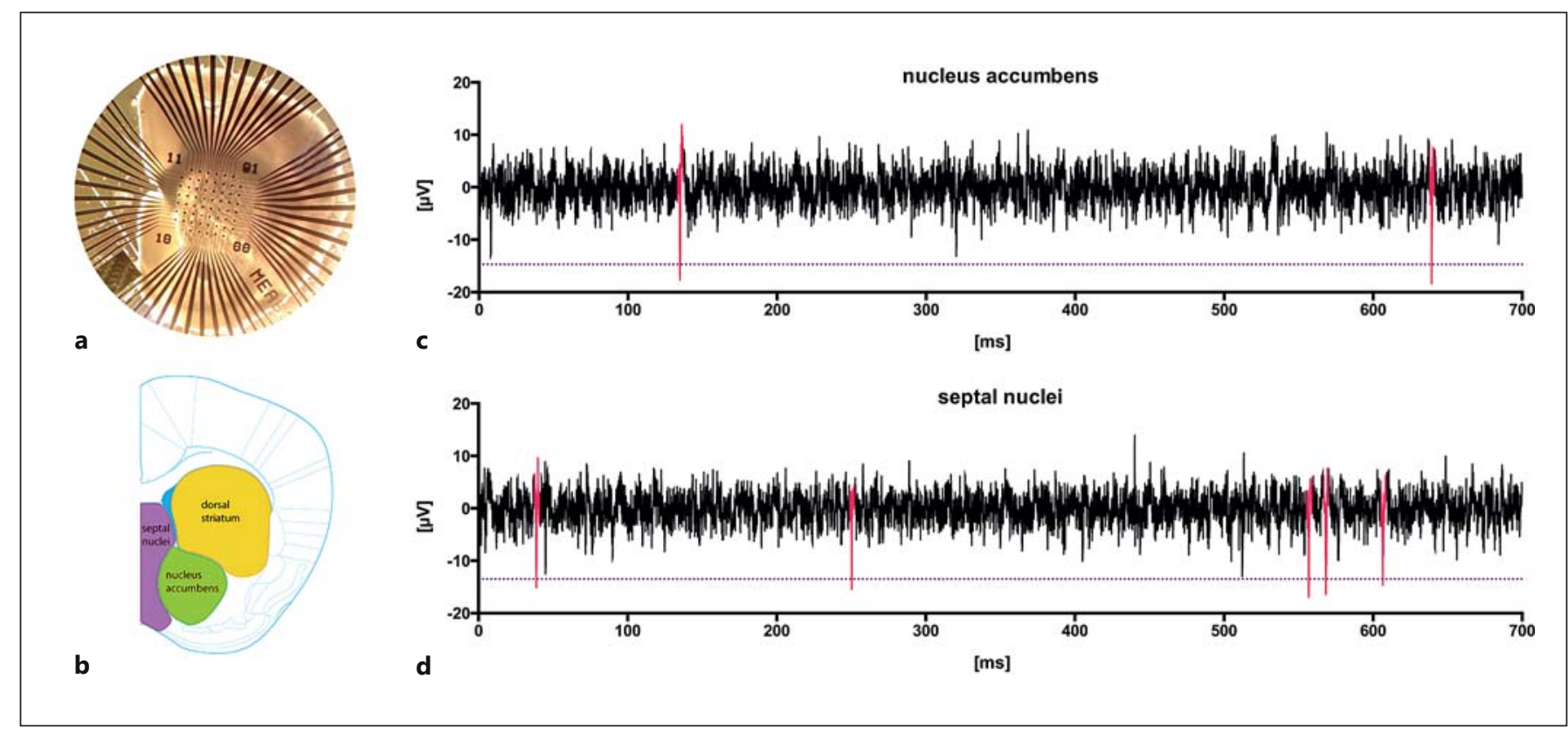

Fig. 1. Brain regions and typical recordings. a Photograph of a coronal slice mounted on the MEA. b A schematic of the recorded regions as well as sample recordings from the nucleus accumbens (c) and the septal nuclei (d), with detected spikes shown in red. The dotted line indicates the threshold of 5 SD from noise.

test, sal vs. int, $\mathrm{p}=0.017$; $\mathrm{p}$ value corrected for 3 multiple comparisons).

In the septal nuclei, the median spike frequencies reached the highest level in mice conditioned to cocaine, and they were significantly increased in comparison to those in saline controls (table 2; sal $0.28 \mathrm{~Hz}, \operatorname{coc} 0.49 \mathrm{~Hz}$, int $0.36 \mathrm{~Hz}$; Kruskal-Wallis $\mathrm{H}$ test, $\mathrm{p}=0.027, \mathrm{H}=7.20$; post hoc Dunn's multiple comparisons test, sal vs. coc, $p=0.025$; $p$ value corrected for 3 multiple comparisons).

In contrast, the mean frequencies were similar for all conditions in the dorsal striatum (table 2; sal $0.11 \mathrm{~Hz}, \mathrm{coc}$ $0.14 \mathrm{~Hz}$, int $0.12 \mathrm{~Hz}$; Kruskal-Wallis $\mathrm{H}$ test, $\mathrm{p}=0.24, \mathrm{H}=$ 2.82). Furthermore, there was no difference between animals showing CPP or CPA for social interaction in any of the investigated regions.

Social interaction-conditioned mice showed significantly fewer sites of spontaneous activity in the nucleus accumbens as compared to saline control mice (table 3; sal 9.9\%, coc 7.7\%, int 6.2\%; $\chi^{2}$ (total), $\mathrm{p}=0.024, \chi^{2}=7.46$, Cramer's V = 0.06; post hoc $\chi^{2}$, sal vs. int, $\mathrm{p}=0.019, \chi^{2}=$ 7.49; $\mathrm{p}$ value Bonferroni-corrected for 3 comparisons).

In the dorsal striatum, social interaction-conditioned mice showed significantly fewer sites of spontaneous activity in comparison to cocaine-treated mice (table 3; sal $12.4 \%, \operatorname{coc} 13.7 \%$, int $10.9 \% ; \chi^{2}$ (total), $p=0.018, \chi^{2}=8.07$,

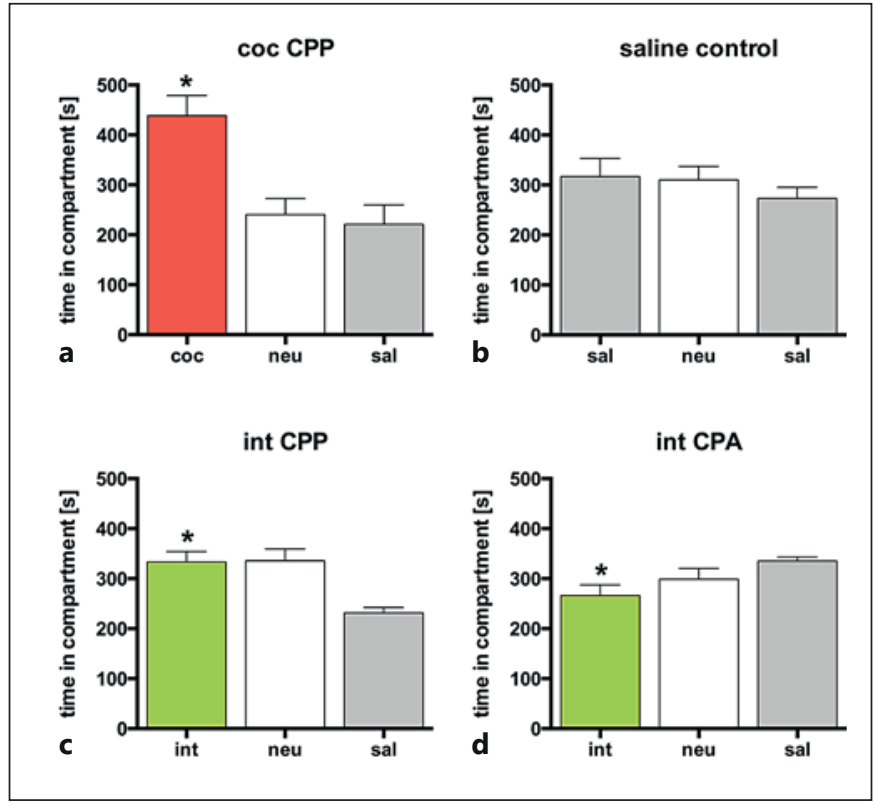

Fig. 2. Behavioral experiments using cocaine versus social interaction CPP. Time spent in the CPP apparatus compartments for mice conditioned to coc CPP $(n=6)(\mathbf{a})$, saline control mice $(n=5)(\mathbf{b})$, and mice conditioned to either int CPP $(n=7)(\mathbf{c})$ or int CPA $(n=$ 5) (d). Shown are group means \pm SEM. neu $=$ Neutral compartment. ${ }^{*} p<0.05$ for time spent in coc/int versus sal (Kruskal-Wallis $\mathrm{H}$ test followed by Dunn's multiple comparisons post hoc test). 
Fig. 3. Distribution of spike frequencies. Median spike frequencies \pm 25 th and 75 th percentile for sal-, coc- and int-conditioned mice in the nucleus (ncl.) accumbens, dorsal striatum and septal nuclei. $* \mathrm{p}<0.05$.

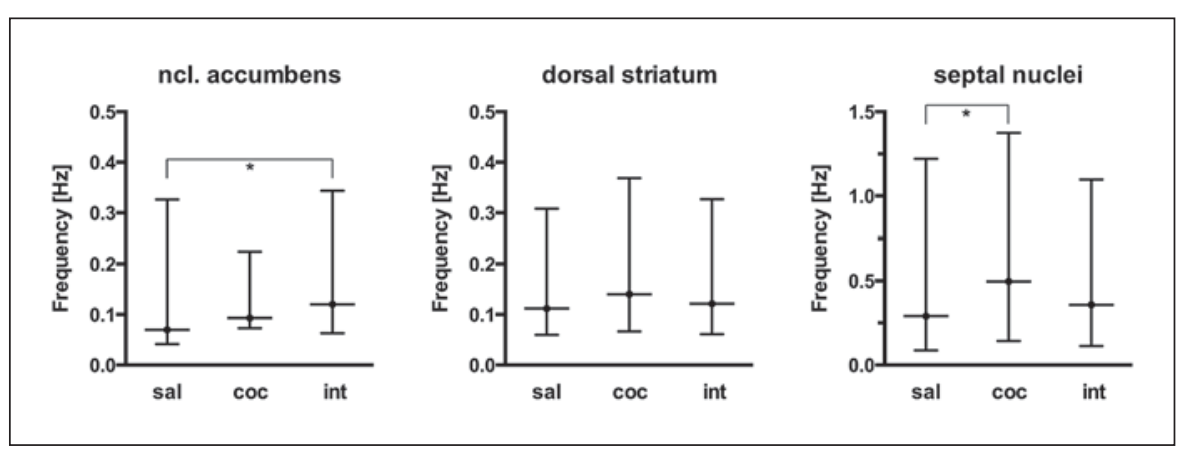

Table 2. Differences in median spike frequencies

\begin{tabular}{|c|c|c|c|c|c|c|c|c|}
\hline & \multicolumn{3}{|c|}{ Median spike frequency, $\mathrm{Hz}$} & \multicolumn{2}{|c|}{ Kruskal-Wallis $\mathrm{H}$} & \multicolumn{3}{|c|}{ Dunn's multiple comparisons, $\mathrm{p}$ value } \\
\hline & sal & $\operatorname{coc}$ & int & $\mathrm{p}$ & $\mathrm{H}$ & sal:coc & sal:int & coc:int \\
\hline Nucleus accumbens & 0.070 & 0.093 & 0.12 & 0.019 & 7.94 & 0.23 & 0.017 & $>0.99$ \\
\hline Dorsal striatum & 0.11 & 0.14 & 0.12 & 0.24 & 2.82 & - & - & - \\
\hline Septal nuclei & 0.28 & 0.49 & 0.36 & 0.027 & 7.20 & 0.025 & 0.82 & 0.16 \\
\hline
\end{tabular}

Median spike frequencies for sal-, coc- and int-conditioned animals in the nucleus accumbens, dorsal striatum and septal nuclei, as well as the statistical analysis (Kruskal-Wallis H test followed by Dunn's multiple comparisons test; p value corrected for 3 multiple comparisons).

Table 3. Differences in electrically active sites

\begin{tabular}{|c|c|c|c|c|c|c|c|c|c|}
\hline & \multicolumn{3}{|c|}{ Active:inactive (\%) } & \multicolumn{3}{|c|}{$\chi^{2}$ (total) } & \multicolumn{3}{|c|}{ Post hoc $\chi^{2}$ ( $\mathrm{p}$ value $)$} \\
\hline Dorsal striatum & $182: 1,284(12.4)$ & $209: 1,320(13.7)$ & $344: 2,819(10.9)$ & 8.07 & 0.018 & 0.036 & 0.92 & 0.37 & 0.016 \\
\hline Septal nuclei & $195: 327(37.4)$ & $184: 393(31.9)$ & $386: 811(32.2)$ & 4.98 & 0.083 & 0.047 & 0.17 & 0.12 & $>0.99$ \\
\hline
\end{tabular}

Proportions of active versus inactive electrodes for sal-, coc- and int-conditioned animals in the nucleus accumbens, dorsal striatum and septal nuclei, as well as results of the statistical analysis $\left[\chi^{2}\right.$ (total) followed by post hoc $\chi^{2}$ ( $\mathrm{p}$ value); $\mathrm{p}$ value corrected for 3 multiple comparisons].

Cramer's $\mathrm{V}=0.04$; post hoc $\chi^{2}$, coc vs. int, $\mathrm{p}=0.016, \chi^{2}=$ 7.74; $\mathrm{p}$ value Bonferroni-corrected for 3 comparisons).

No difference was found between treatment groups in the septal nuclei (table 3; sal 37.4\%, coc 31.9\%, int 32.2\%, $\mathrm{p}=0.083, \chi^{2}=4.98$, Cramer's $\mathrm{V}=0.05$ ).

\section{Correlation of Spike Frequencies and Cocaine and \\ Social Interaction Conditioning}

Although differences in electrical network activities were observed in the nucleus accumbens, dorsal striatum and septal nuclei, no significant correlation between the time spent in the cocaine-paired compartment and spike frequencies of any of the brain regions was obtained (data not shown).

However, the spike frequencies in the septal nuclei, but not those in the nucleus accumbens or dorsal striatum, were inversely correlated with the time spent in the social interaction-paired compartment (Spearman correlation; $\mathrm{p}=0.043, \mathrm{r}=-0.60)$. 


\section{Discussion}

In the present study, we used in vitro extracellular MEA recordings of acute mouse brain slices containing the nucleus accumbens core and shell (i.e., nucleus accumbens), the medial and lateral septum (i.e., septal nuclei) as well as the dorsal striatum to assess signatures of network activity underlying reward conditioning.

In saline-treated control mice, different proportions of sites produced spontaneous activity in the nucleus accumbens and the striatum (i.e., 9.9 and $12.4 \%$ active electrodes, respectively) as well as the septal nuclei (i.e., $37.4 \%$ active electrodes). This difference could be explained by the different neuron populations present in these regions. In the nucleus accumbens and the striatum, the predominant neuron type are GABAergic projection neurons for which spontaneous network activity in vitro is controversial, and irregular spike discharges can occur [18-20]. Five different interneuron types account for a few percent of the whole neuronal population [21]. Of those, cholinergic interneurons and $\mathrm{NPY}^{+}$GABAergic interneurons show regular electrical activity in vitro, which is independent of synaptic input [18, 22-24]. Thus, it seems likely that the spontaneously active neurons we recorded in these regions are these different types of interneurons. The septal region can be divided into the lateral septum, containing mainly GABAergic neurons which coexpress calretinin or calbindin but not parvalbumin (PV) [25], and the medial septum. This contains GABAergic neurons ( $75 \%$ of total neurons), some coexpressing $\mathrm{PV}$ $(\sim 35 \%)$, cholinergic neurons $(\sim 9 \%)$ and glutamatergic neurons $[26,27]$. Both subregions are known to contain spontaneously active neurons, and in the medial septum, $\mathrm{PV}^{+} \mathrm{GABA}$ ergic neurons have been found to be fast spiking $[28,29]$. In the present study, the septum showed a higher median action potential firing frequency $(0.28 \mathrm{~Hz})$ compared to the nucleus accumbens and the striatum (0.07 and $0.11 \mathrm{~Hz}$, respectively). Both the higher spike frequency and the higher prevalence of spontaneously active cells suggest that the neurons recorded in the medial septum were fast-spiking $\mathrm{PV}^{+}$GABAergic neurons.

Conditioning to cocaine as a prototypical drug reward resulted in a significant increase in activity in the septal nuclei. However, the spike frequency was not correlated to the time spent in the cocaine-paired compartment. One possible explanation for this finding is enhanced excitatory input to a specific type of neurons in the septal nuclei due to cocaine application, which has been shown at least for other brain regions [30-33].

Social Interaction and Cocaine

Conditioning in Mice
Place conditioning for social interaction decreased the number of neurons that were spontaneously active in the nucleus accumbens; however, those neurons that still fired did so at a higher rate. One possible explanation for these findings is that social interaction leads to a stronger activation of an inhibitory neuron type that then fires at a higher frequency and therefore inhibits the other spontaneously active neurons. This activation could also be due to increased excitatory synaptic input to that specific neuron type. Interestingly, animals expressing CPP or CPA for social interaction did not differ in their electrical activity in any of the investigated regions. This suggests that the increased spontaneous activity in the nucleus accumbens is not related to the different behavioral outcomes of CPP or CPA for social interaction.

It is commonly accepted that the nucleus accumbens is involved in reward and addiction [for reviews, see 3436]. However, the involvement of septal nuclei in brain circuits for addiction is less clear. Olds and Milner [37] showed that electrical self-stimulation had the most reliable reward effect if performed in the septal region, and strong connections exist between the septal nuclei and other brain regions of the reward pathway [28, 38-41]. The current work thus for the first time presents direct evidence of an alteration in network activity in this region that is associated with drug and natural reward conditioning. These electrophysiological findings are reminiscent of activation data obtained with IEG markers that indicate that conditioning to cocaine or dyadic social interaction does not only engage the nucleus accumbens proper but involves the neighboring regions as well [5].

So far, network activity in different neuron types has mainly been assessed in the nucleus accumbens; however, reports so far are inconsistent and the cellular mechanisms that generate the spontaneous activity are unknown [18$20,23,24,42]$. The hyperpolarization-activated cyclic nucleotide-gated channels have been associated with spontaneous pacemaker activity [43], and $\mathrm{PV}^{+}$GABAergic neurons in the medial septum express hyperpolarization-activated cyclic nucleotide-gated channels [44]. Although in the nucleus accumbens different hyperpolarization-activated cyclic nucleotide-gated subunits have been discovered, it is so far unknown which neuron types express these channels to generate pacemaker activities [45, 46].

In summary, our results for the first time demonstrate that reward conditioning for both drug or natural reward leads to increased electrical network activity in the septal nuclei or the nucleus accumbens, but not in the dorsal striatum, which did not seem to be affected by reward conditioning. The increased neuronal activation in areas 
relevant for the reward system indicates persistent changes induced by drug and social interaction reward in neuronal networks.

\section{Acknowledgements}

This work was supported by the Austrian Science Fund (FWF) graduate program 'Signal Processing in Neurons' (SPIN, www. neurospin.at; FWF grant W1206-B18 to A.S.), and by FWF grants
P26248-B24 (to G.Z.) and P23824-B18 (to R.E.R.). We would like to cordially thank Dr. Ulrich Egert for his helpful methodological advice.

\section{Disclosure Statement}

The authors declare that the research was conducted in the absence of any commercial or financial relationships that could be construed as a potential conflict of interest.

\section{References}

1 Grawe K, Donati R, Bernauer F: Psychotherapie im Wandel: Von der Konfession zur Profession, ed 3. Göttingen, Hogrefe, 1994.

$\checkmark 2$ Leichsenring F, Rabung S, Leibing E: The efficacy of short-term psychodynamic psychotherapy in specific psychiatric disorders: a meta-analysis. Arch Gen Psychiatry 2004;61: 1208-1216.

3 Zernig G, Kummer KK, Prast JM: Dyadic social interaction as an alternative reward to cocaine. Front Psychiatry 2013;4:100.

-4 Fritz M, El Rawas R, Salti A, Klement S, Bardo MT, Kemmler G, Dechant G, Saria A, Zernig G: Reversal of cocaine-conditioned place preference and mesocorticolimbic Zif268 expression by social interaction in rats. Addict Biol 2011;16:273-284.

-5 Prast JM, Schardl A, Schwarzer C, Dechant G, Saria A, Zernig G: Reacquisition of cocaine conditioned place preference and its inhibition by previous social interaction preferentially affect D1-medium spiny neurons in the accumbens corridor. Front Behav Neurosci 2014;8:317.

6 Fritz M, El Rawas R, Klement S, Kummer K, Mayr MJ, Eggart V, Salti A, Bardo MT, Saria A, Zernig G: Differential effects of accumbens core vs shell lesions in a rat concurrent conditioned place preference paradigm for cocaine vs social interaction. PLoS One 2011;6:e26761.

7 Kummer KK, Hofhansel L, Barwitz CM, Schardl A, Prast JM, Salti A, El Rawas R, Zernig G: Differences in social interaction- vs cocaine reward in rat vs mouse. Front Behav Neurosci 2014;8:363.

8 El Rawas R, Klement S, Kummer KK, Fritz M, Dechant G, Saria A, Zernig G: Brain regions associated with the acquisition of conditioned place preference for cocaine vs social interaction. Front Behav Neurosci 2012;6:63.

-9 Gass JT, Olive MF: Glutamatergic substrates of drug addiction and alcoholism. Biochem Pharmacol 2008;75:218-265.

10 Kalivas PW, McFarland K: Brain circuitry and the reinstatement of cocaine-seeking behavior. Psychopharmacology 2003;168:44-56.
1 Marinelli M, White FJ: Enhanced vulnerability to cocaine self-administration is associated with elevated impulse activity of midbrain dopamine neurons. J Neurosci 2000;20:88768885.

12 Kelley AE, Berridge KC: The neuroscience of natural rewards: relevance to addictive drugs. J Neurosci 2002;22:3306-3311.

13 Pitchers KK, Vialou V, Nestler EJ, Laviolette SR, Lehman MN, Coolen LM: Natural and drug rewards act on common neural plasticity mechanisms with deltaFosB as a key mediator. J Neurosci 2013;33:3434-3442.

14 Chaudhuri A: Neural activity mapping with inducible transcription factors. Neuroreport 1997;8:iii-vii.

15 Clayton DF: The genomic action potential. Neurobiol Learn Mem 2000;74:185-216.

16 Bischofberger J, Engel D, Li L, Geiger JR, Jonas P: Patch-clamp recording from mossy fiber terminals in hippocampal slices. Nat Protoc 2006;1:2075-2081.

17 Ting JT, Daigle TL, Chen Q, Feng G: Acute brain slice methods for adult and aging animals: application of targeted patch clamp analysis and optogenetics. Methods Mol Biol 2014;1183:221-242.

18 Kawaguchi Y: Large aspiny cells in the matrix of the rat neostriatum in vitro: physiological identification, relation to the compartments and excitatory postsynaptic currents. J Neurophysiol 1992;67:1669-1682.

19 Ibanez-Sandoval O, Tecuapetla F, Unal B, Shah F, Koos T, Tepper JM: Electrophysiological and morphological characteristics and synaptic connectivity of tyrosine hydroxylase-expressing neurons in adult mouse striatum. J Neurosci 2010;30:6999-7016.

20 Plenz D, Kitai ST: Up and down states in striatal medium spiny neurons simultaneously recorded with spontaneous activity in fastspiking interneurons studied in cortex-striatum-substantia nigra organotypic cultures. J Neurosci 1998;18:266-283.

21 Kreitzer AC: Physiology and pharmacology of striatal neurons. Annu Rev Neurosci 2009; 32:127-147.
22 Beatty JA, Sullivan MA, Morikawa H, Wilson CJ: Complex autonomous firing patterns of striatal low-threshold spike interneurons. J Neurophysiol 2012;108:771-781.

23 Bennett BD, Wilson CJ: Spontaneous activity of neostriatal cholinergic interneurons in vitro. J Neurosci 1999;19:5586-5596.

-24 Tepper JM, Tecuapetla F, Koos T, IbanezSandoval O: Heterogeneity and diversity of striatal GABAergic interneurons. Front Neuroanat 2010;4:150.

25 Zhao C, Eisinger B, Gammie SC: Characterization of GABAergic neurons in the mouse lateral septum: a double fluorescence in situ hybridization and immunohistochemical study using tyramide signal amplification. PLoS One 2013;8:e73750.

26 Manseau F, Danik M, Williams S: A functional glutamatergic neurone network in the medial septum and diagonal band area. J Physiol 2005;566:865-884.

-27 Simon AP, Poindessous-Jazat F, Dutar P, Epelbaum J, Bassant MH: Firing properties of anatomically identified neurons in the medial septum of anesthetized and unanesthetized restrained rats. J Neurosci 2006;26:90389046.

28 McLennan H, Miller JJ: The hippocampal control of neuronal discharges in the septum of the rat. J Physiol 1974;237:607-624.

29 Morris NP, Harris SJ, Henderson Z: Parvalbumin-immunoreactive, fast-spiking neurons in the medial septum/diagonal band complex of the rat: intracellular recordings in vitro. Neuroscience 1999;92:589-600.

30 Campanac E, Hoffman DA: Repeated cocaine exposure increases fast-spiking interneuron excitability in the rat medial prefrontal cortex. J Neurophysiol 2013;109:2781-2792.

31 Huang CC, Lin HJ, Hsu KS: Repeated cocaine administration promotes long-term potentiation induction in rat medial prefrontal cortex. Cereb Cortex 2007;17:1877-1888.

32 Liu QS, Pu L, Poo MM: Repeated cocaine exposure in vivo facilitates LTP induction in midbrain dopamine neurons. Nature 2005; 437:1027-1031. 
33 Pascoli V, Terrier J, Espallergues J, Valjent E, O'Connor EC, Luscher C: Contrasting forms of cocaine-evoked plasticity control components of relapse. Nature 2014;509:459-464.

-34 Carelli RM, Wightman RM: Functional microcircuitry in the accumbens underlying drug addiction: insights from real-time signaling during behavior. Curr Opin Neurobiol 2004; 14:763-768.

35 Kalivas PW, Volkow N, Seamans J: Unmanageable motivation in addiction: a pathology in prefrontal-accumbens glutamate transmission. Neuron 2005;45:647-650.

36 Quintero GC: Role of nucleus accumbens glutamatergic plasticity in drug addiction. Neuropsychiatr Dis Treat 2013;9:1499-1512.

37 Olds J, Milner P: Positive reinforcement produced by electrical stimulation of septal area and other regions of rat brain. J Comp Physiol Psychol 1954;47:419-427.
38 Sheehan TP, Chambers RA, Russell DS: Regulation of affect by the lateral septum: implications for neuropsychiatry. Brain Res Brain Res Rev 2004;46:71-117.

39 Gulyas AI, Hajos N, Katona I, Freund TF: Interneurons are the local targets of hippocampal inhibitory cells which project to the medial septum. Eur J Neurosci 2003;17:18611872.

40 Hangya B, Borhegyi Z, Szilagyi N, Freund TF, Varga V: GABAergic neurons of the medial septum lead the hippocampal network during theta activity. J Neurosci 2009;29:8094-8102.

41 Powell EW, Leman RB: Connections of the nucleus accumbens. Brain Res 1976;105:389403.

42 Koos T, Tepper JM: Inhibitory control of neostriatal projection neurons by GABAergic interneurons. Nat Neurosci 1999;2:467-472.
3 Chen J, Piper DR, Sanguinetti MC: Voltage sensing and activation gating of $\mathrm{HCN}$ pacemaker channels. Trends Cardiovasc Med 2002;12:42-45.

44 Varga V, Hangya B, Kranitz K, Ludanyi A, Zemankovics R, Katona I, Shigemoto R, Freund TF, Borhegyi Z: The presence of pacemaker $\mathrm{HCN}$ channels identifies theta rhythmic GABAergic neurons in the medial septum. J Physiol 2008;586:3893-3915.

45 Notomi T, Shigemoto R: Immunohistochemical localization of Ih channel subunits, HCN1-4, in the rat brain. J Comp Neurol 2004;471:241-276.

46 Santos-Vera B, Vazquez-Torres R, Marrero HG, Acevedo JM, Arencibia-Albite F, VelezHernandez ME, Miranda JD, Jimenez-Rivera CA: Cocaine sensitization increases I h current channel subunit $2\left(\mathrm{HCN}_{2}\right)$ protein expression in structures of the mesocorticolimbic system. J Mol Neurosci 2013;50:234-245. 